\title{
Correction to: Chemical communication in springtails: a review of facts and perspectives
}

\author{
Sandrine Salmon ${ }^{1} \cdot$ Sylvie Rebuffat ${ }^{2} \cdot$ Soizic Prado ${ }^{2} \cdot$ Michel Sablier $^{3} \cdot$ Cyrille D'Haese $^{1} \cdot$ Jian-Sheng Sun $^{4}$. \\ Jean-François Ponge ${ }^{1}$
}

Published online: 22 April 2020

(C) Springer-Verlag GmbH Germany, part of Springer Nature 2020

Correction to: Biology and Fertility of Soils (2019) 55:425-438

https://doi.org/10.1007/s00374-019-01365-8

The authors regret that the original published version of the above article contained an error at the beginning of the subsection "Sex pheromones" (page 428 of the published version) within the section "The use of pheromones, allomones and kairomones by Collembola". The original two sentences, "Sex pheromones can be produced by females, conditioning the deposition of spermatophores by males (Waldorf 1974a). They can be also produced by males, attracting females directly (Porco et al. 2009) or indirectly through their spermatophores (Zizzari et al. 2017)." should be read as "Sex pheromones are produced by females, conditioning the deposition of spermatophores by males (Waldorf 1974a) and attracting them (Porco et al. 2009) while spermatophores produced by males are also known to attract females (Zizzari et al. 2017)." [Bold text used to highlight problem area]

The online version of the original article can be found at https://doi.org/ 10.1007/s00374-019-01365-8

Jean-François Ponge

ponge@mnhn.fr

1 Département Adaptations du Vivant, UMR 7179 MECADEV, Muséum National d'Histoire Naturelle, 4 avenue du Petit Château, Brunoy, 91800 Paris, France

2 Département Adaptations du Vivant, UMR 7245 MCAM, Muséum National d'Histoire Naturelle, 57 rue Cuvier, CP 54, 75005 Paris, France

3 Département Origines et Évolution, Muséum National d'Histoire Naturelle, USR 3224 CRC, 57 rue Cuvier, CP 21, 75005 Paris, France

4 Département Adaptations du Vivant, Muséum National d'Histoire Naturelle, 57 rue Cuvier, CP 26, 75005 Paris, France 